\title{
Acciones de interés público y enseñanza del Derecho: sobre paradigmas y utopías*
}

Gorki Gonzales Mantilla

\section{Presentación}

El presente documento intenta definir la existencia de una especial articulación entre la comprensión de lo jurídico derivada de las investigaciones en materia de acciones de interés público y el proceso que involucra el contexto de la enseñanza del Derecho. Se trata, en todo caso, de presentar las líneas interpretativas que desde las investigaciones en materia de acciones de interés público permiten identificar y postular tendencias y posibilidades.

Partimos de formular la siguiente consideración: frente a la idea del Derecho como espacio unidimensional o como simple reflejo de voluntades políticas dominantes, construido como elemental testimonio escrito del Poder del Estado, las reflexiones en materia de acciones de interés público producen, como consecuencia necesaria, el valorar aquello que permite la convivencia y la viabilidad de una comunidad de individuos en términos de tolerancia, pluralismo y democracia.

La perspectiva de la cual se pretende dar cuenta, vislumbra, aunque todavía inicialmente, la necesidad de incorporar nuevos mecanismos de aproximación a lo jurídico, para detectarlo tanto como para hacerlo viable en el mismo espacio del Derecho tradicional, para litigar con él y por último para vencerlo en su propio campo.

La reflexión y la crítica surgidas a propósito de las investigaciones en materia de acciones de interés público, brindan pautas sustantivas

* Documento presentado al Taller sobre Investigaciones en Materias de Interés Público - Santiago de Chile, 19-20 de octubre de 1999 
y metodológicas vinculadas íntegramente a la noción de cómo enseñar y cómo incorporar en dicho proceso la comprensión de lo jurídico como una dimensión más compleja que la derivada del principio de legalidad. Podría decirse, sin temor a error, que las acciones de interés público son, entonces, una herramienta que permite entender lo jurídico a partir de su realidad antes que de sus formas y, por ello, se convierten en un ámbito desde el cual se puede ejercer algún tipo de énfasis en la particular estructura ideológica sobre la que descansan los postulados del derecho moderno auspiciados y difundidos desde nuestras facultades de Derecho.

\section{En búsqueda de nuevos paradigmas para la enseñanza del Derecho: (resumen ejecutivo del proyecto)}

Las investigaciones en materia de acciones de interés público forman parte de un proyecto iniciado hace dos años y medio que tuvo como supuestos de hecho i) el debilitamiento de las instituciones representativas de la sociedad civil, como consecuencia de las denominadas medidas de ajuste económico y político; y, ii) la necesidad de articular nuevos mecanismos aptos para salvaguardar los intereses sociales e individuales emergentes de este nuevo contexto.

En su desarrollo temático se han abordado cuestiones diversas: la protección de los derechos fundamentales; la defensa del medio ambiente; el respeto de la diversidad cultural; el respeto del principio de la no discriminación; así como la eficacia de las instituciones públicas y de la función jurisdiccional como instancia privilegiada frente al tema. El marco de referencia de todas estas investigaciones ha sido el caso peruano y producto de dicha reflexión se ha propiciado un amplio espacio de discusión sustantivo y también metodológico en certámenes inter-institucionales en el ámbito local y nacional. En estos encuentros han confluido profesores de la Pontificia Universidad Católica del Perú, de la Universidad Nacional de San Agustín y de otras universidades nacionales y privadas del país, representantes de la Defensoría del Pueblo, investigadores del Instituto de Defensa Legal, miembros de la Sociedad Peruana de Derecho Ambiental, magistrados del Poder Judicial, estudiantes universitarios, etc.

Como producto de la novedad que involucra la temática y su particular inserción metodológica en la comprensión de «lo jurídico», se 
ha propiciado la formación de clínicas jurídicas tanto en la PUCP como en la UNSA. Estas instituciones, formadas por profesores y estudiantes, han permitido desarrollar el discurso proveniente de las investigaciones, en busca de reconceptualizar el lugar de «los derechos", así como redefinir sus mecanismos de protección a partir de casos concretos. Tanto de este ámbito como de la incorporación temática en el discurso del grupo de referencia que confluye en el proyecto, se han desarrollado contenidos a partir de los cuales ha sido posible formular materias de enseñanza regular en la Facultad de Derecho de la PUCP.

El objetivo central de todo este desarrollo busca configurar elementos que permitan hablar de un paradigma sobre "lo jurídico" y sobre la enseñanza del derecho, superando los postulados que resumen lo primero al conjunto de normas positivas y a la transmisión de conocimientos de una realidad dada -a partir de la hermenéutica y la labor de subsunción lógica-, en el caso de lo segundo.

Las investigaciones en materia de acciones de interés público pueden asumirse, en tal sentido, como un trabajo que se inicia en el gabinete, pero que continúa a lo largo de un proceso de retroalimentación permanente: Una evolución dinámica que incide tanto en la definición de pistas teóricas sobre lo jurídico, como en la formulación de aproximaciones metodológicas para su comprensión no disociada de la realidad.

III Las acciones de interés público como ámbito de reflexión y sus implicancias en la re-definición de lo jurídico (avances, logros e impactos del trabajo realizado)

La concepción positivista-normativista es, en el proceso histórico del desarrollo cultural de occidente, la visión que más ha perfilado su presencia -por decir lo menos- en la formación de los juristas. Es ella la que se ha consolidado y generalizado como fórmula de penetración analítica y sistemática del Derecho. Más aún, en el caso peruano, el apego literal a la ley, independientemente del contexto que configura el núcleo materia de la controversia, ha sido el ámbito de influencia inevitable para quienes se han formado en la disciplina de «lo jurídico" en nuestras facultades de Derecho. Se puede sostener que no obs- 
tante las críticas a este modelo, al final se nos presenta cual círculo de hierro infranqueable, pero además como una costumbre inveterada que resulta imposible dejar de lado, pues se teme caer en el vacío. Es lo que bien podría denominarse un "paradigma" compartido por la comunidad de quienes habitan el mundo del quehacer jurídico. Un paradigma fundado en la aceptación del positivismo-normativista tal cual es. En otras palabras, porque se cree en su verdad, en su validez y en su vigencia, haciéndolo nuestro como "verdad" y como instrumento de «moralidad".

Al interior de esta visión, la enseñanza del Derecho adquiere un valor «esencial" para la reproducción de los valores, percepciones y actitudes del futuro operador jurídico. Y el profesor de Derecho tiene, entonces, un papel central: es el iniciador de un rito que convoca a una comunidad creciente de jóvenes ávidos de pertenecer a esta feligresía, donde el objeto de adoración -el Derecho entendido casi habitualmente como sinónimo de ley- se "enseña" como algo dado e incuestionable desde tal perspectiva, sin ambición crítica que no sea la vinculada a su aplicación al caso concreto. La labor docente es vista como una actividad técnica: aprender la hemenéutica para analizar la norma y entender su significado que ya está dado, cual palabra divina, en la norma misma. Técnica porque no se busca teorizar sino para entender las propias particularidades del rito, hacia dentro. Importa básicamente entrenarse para no incurrir en pecado o sacrilegio. Por ello, la propia dinámica docente tiene su particular metodología o apostolado: transmitir los "conocimientos» para que sean recibidos por los iniciados.

En buena medida, la perspectiva propiciada por las investigaciones en materia de acciones de interés público ha demostrado que es posible adelgazar el círculo de hierro, desgastar el material del que está hecho y abrir espacios para escapar de su aprehensión. Y en ese tránsito, nuestro proyecto ha buscado reflejar el creciente proceso de desarticulación institucional que confronta de manera inacabable el Perú y que sesga la actuación de lo político en función de valores coyunturales, afinados al oído del régimen político que ya tiene diez años orquestando y que busca difundir su música durante un quinquenio más. En efecto, el proyecto en cuestión ha buscado poner en relieve la existencia de un conjunto de valores y necesidades de la sociedad civil que, por ser tales, es decir, imprescindibles como realidades para 
su convivencia y desarrollo deben ser incorporados en la agenda política del Estado como bienes jurídicos básicos.

Hablamos de un ámbito denominado "interés público" que no se refleja ya como el del Estado, sino como aquel que deriva de las necesidades básicas, no en función de los individuos sino de la comunidad a la que pertenecen y los agrupa. En este nivel se ha podido establecer la incorporación de estas «necesidades» en el denominador «derechos fundamentales» como expresión de los acuerdos que hacen viable su satisfacción como bienes jurídicos de interés público. Conexa a esta visión, el mecanismo de tutela o protección de estos bienes jurídicos ha sido objeto de revisión para afinar la mira. Se trata de todo mecanismo o "acción», referido a la protección de un derecho fundamental, en forma directa o indirecta. No es relevante, en su comprensión conceptual, que la interposición se produzca frente al Poder Judicial u otra entidad pública con poder para decidir o para influir en la decisión que resuelva el asunto.

Las investigaciones en materia de acciones de interés público desarrolladas al interior del Proyecto, emprendiendo el reto de re-pensar lo jurídico a partir de esta perspectiva han venido construyendo una estructura flexible, atenta a los problemas sociales más críticos. ${ }^{1} \mathrm{La}$ protección de los derechos fundamentales, ${ }^{2}$ la defensa del medio ambiente, ${ }^{3}$ el respeto de la diversidad cultural, ${ }^{4}$ la defensa del principio de la no discriminación en el ámbito laboral ${ }^{5}$ y en el rubro de los servi-

1 Gorki Gonzales «Relatoría sobre las acciones de interés público en el Perú». En: Las Acciones de Interés Público. Argentina, Chile, Colombia y Perú. Cuadernos de Análisis Jurídicos $\mathrm{N}^{\circ}$ 7, Facultad de Derecho de la Universidad Diego Portales de Chile. (Felipe González, editor), 1997, pp. 151-197.

2 César Azabache "Acciones de interés público y derechos fundamentales en el Perú". En: Las Acciones de Interés Público. Argentina, Chile, Colombia y Perú. Ob. Cit. pp. 201241.

3 Carlos Chirinos Arrieta. La defensa del medio ambiente y las acciones de interés en el Perú. Documento, Lima, 1996.

4 Antonio Peña. Justicia de paz y justicia comunal. Documento, Lima, 1996.

5 Paul Paredes. "Discriminación en el empleo tras la política laboral de ajuste y estabilización de la economía (1991-1997). Justificación para más de una acción de interés públicon. En: Ciudadanía e interés público. Enfoques desde el Derecho, la Ciencia Política y la Sociología. Cuadernos de Análisis Jurídicos $N^{\circ} 8$, Facultad de Detecho de la Universidad Diego Portales de Chile. pp. 63-79. 
cios públicos, ${ }^{6}$ la defensa de los derechos laborales, ${ }^{7}$ asi como la eficacia de las instituciones públicas y de la función jurisdiccional como instancia privilegiada frente al tema. ${ }^{8}$

Las particularidades de esta "visión", que presenta lo jurídico como instrumento cotidiano de las personas para relacionarse entre sí y establecer formas de convivencia, antes que como simple imposición estatal, han propiciado un discurso emergente encadenado a la enseñanza del Derecho. Tanto en el plano sustantivo como en el metodológico se han venido formulando estrategias para dar contenido a un nuevo paradigma.

a) El producto y la reflexión emanada de estas investigaciones han devenido contenidos lectivos de nuestra Facultad de Derecho. En el Seminario de Integración en Teoría General del Derecho, ${ }^{9}$ semestre a

6 Alfredo Bullard. «Las acciones de interés público en defensa de la libre competencia y la protección del consumidor: el caso peruanom. En: Las Acciones de Interés Público. Argentina, Chile, Colombia y Perú. Ob. Cit. pp. 243-286.

7 Javier Neves Mujica. "Acciones de interés público en materia laboral». En: Defensa del Interés Jurídico. Enseñanza, estrategias, experiencias. Cuadernos de Análisis Jurídico $\mathrm{N}^{\circ}$ 9 , Facultad de Derecho de la Universidad Diego Portales de Chile, 1999, pp- 127-147.

8 Gorki Gónzales. Poder Judicial, Interés Público y Derechos Fundamentales en el Perú. Lima: Pontificia Universidad Católica del Perú - Universidad Diego Portales de Chile, 1998.

9 La presentación del Syllabus del curso Seminario de Integración en Teoría General del Derecho, (dictado por primera vez en el segundo semestre de 1998) cuya coordinación estuvo a cargo del profesor René Ortiz Caballero dice: "Por la identidad de los cursos que componen el área de Teoría General del Derecho, se puede sostener que ésta concierne a aquellas perspectivas académicas de "re- flexión" sobre el Derecho en sus distintas manifestaciones; se trata de materias que reciben el carácter de jurídicas porque tienen al Derecho como objeto, sea para introducir a su conocimiento mediante la presentación de los métodos jurídicos principales, sea para examinarlo con métodos de otras disciplinas o para realizar una reflexión sobre su evolución y nuevas manifestaciones. No versa sobre unas materias específicas sino que alcanza a todos los campos del Derecho, si bien con distintos grados o matices de aproximación.

En la actualidad, el Seminario de Integración en Teoría General del Derecho ha diversificado sus horarios e incrementado el número de profesores y alumnos (cuatro profesores con 25 alumnos por seminario); sin embargo, el punto de referencia para la reflexión en clase sigue siendo básicamente el mismo: el problema que alude a la existencia de conflictos de derechos fundamentales y que involucra en su configuración indicadores que, aparentemente, están más allá de lo "jurídico". Se plantea, entonces, el reto de estudiar en forma sistemática los diversos componentes de la interpretación y la argumentación en el Derecho en la perspectiva de entender que con la promoción de los derechos en cuestión, se defiende algo más que intereses particulares: las instituciones y principios políticos de la democracia y del Estado constitucional. 
semestre, desde hace dos años y medio se debaten, entre otros, los temas anteriormente indicados; es decir, sintonizando la crítica del propio discurso de las denominadas acciones de interés público con los problemas cruciales del país, se ha producido un involucramiento de cuestiones a las que antes sólo se atendía desde el plano político o económico. El citado Seminario permite entender el Derecho como un instrumento reticular impregnado por los otros ordenamientos, cuya naturaleza, en la perspectiva positivista-normativista, no formaban parte de "lo jurídico». El Derecho en esta dimensión más integral deja de ser un círculo de hierro para convertirse en una compleja red que vincula los componentes de la vida social, impregnándolos de sentido y funcionalidad.

La función docente enfrenta, por lo tanto, un gran reto: razonar jurídicamente no sólo para entender o interpretar lo sustantivo o desarrollar la destreza técnica para formular la estrategia procesal desde las normas positivas para volver a ellas. Un conflicto de derechos, un problema de discriminación o una controversia en torno a la defensa del medio ambiente exige relativizar el principio de legalidad tan consustancial a la tradición occidental. Los valores constitucionales o aquellos que, desde la perspectiva normativista, resultan extra-sistémicos impregnan el ordenamiento social y dan sentido a la vida en comunidad. La comprensión de lo jurídico, en la función docente, se plantea la tarea de incorporar estos valores en la discusión de las reglas jurídicas y en la dilucidación de los casos. La enseñanza del derecho en el contexto propiciado por las acciones de interés público y al interior de este Seminario se plantea como una apuesta abierta a la argumentación antes que a la definición excluyente de los problemas a partir del silogismo.

Por lo mismo, la tarea docente exige la elaboración de materiales de enseñanza. Tarea que no se agota en la selección de textos para su lectura, es preciso, además, que éstos sean objeto de reflexión en el marco de casos reales propuestos para el debate; así, la dinámica metodológica no se disocia de lo que se enseña. El escenario que se presenta a los estudiantes es como sigue: la teoría ligada a la práctica, como dos partes inseparables de un todo, con preguntas que inducen a des-dogmatizar el análisis de los contenidos y que provocan la necesidad de romper la inercia reduccionista del simple razonamiento exegético. Las instituciones tradicionales del Derecho no se enseñan, 
se proponen para ser discutidas. No existen verdades dadas, las nociones de vigencia o validez no son suficientes para arribar a una conclusión definitiva. Interesa formular esquemas de razonabilidad, donde el problema identificado debe ser absuelto más allá de los esquemas reglamentaristas. El alumno deberá formular por escrito el proceso que orienta su razonamiento, discutiendo los asuntos relevantes y proponiendo justificadamente la incorporación de categorías o instituciones antes no consideradas como jurídicas. La consistencia del trabajo radica en la capacidad para repensar lo jurídico, para resolver el caso en armonía con los principios constitucionales o los valores del sistema social, asumiendo las reglas legales como textura abierta.

b) Como extensión de lo anterior, las clínicas jurídicas propiciadas en el marco del proyecto global, son la sala contigua de la misma casa, lo que cambia es la finalidad particular del espacio. Los alumnos enfrentan los problemas recogidos de la realidad para asumirlos con el respaldo del profesor (en realidad el docente en este ámbito es solo un facilitador). Pero lo fundamental es que la clínica, como tal, se convierte en un valor agregado al proceso de investigación en materia de acciones de interés público. Es desde ella que se enfrentan los obstáculos impuestos por las reglas del sistema o por su carencia. Si bien es el caso concreto el que motiva el trabajo inicial, el equipo de estudiantes, bajo la orientación docente, desarrolla una función que busca trascender del caso concreto -sin perderlo nunca de vista-, pues la operación busca remediar no un mal individual sino un problema epidémico. En efecto, en la perspectiva de las acciones de interés público, es importante la relevancia social del caso, tanto como el enfoque que asume la estrategia de defensa: es fundamental que se trate de un asunto en el que se cuestionen reglas básicas del sistema o se lesionen derechos fundamentales.

El razonamiento debe encarar el caso en su contexto, incorporando en él las variables necesarias para que la solución contribuya a «enderezar» el sistema legal en cuestión: para poner en evidencia la inconsistencia de un ordenamiento que se presenta formalmente como defensor de los derechos humanos, pero que subordina la vigencia de los mismos al principio de legalidad, una legalidad impuesta por las necesidades fácticas del régimen político de turno. El objetivo es abrir espacios en el propio ordenamiento formal, si es necesario, sofisticando al extremo el método de la ciencia jurídica tradicional. Nada de ello 
resulta inconsistente, si en el fondo se trata de re-conducir el instrumental teórico del positivismo-normativista en la perspectiva de una noción de lo jurídico que no se agota en éste. ${ }^{10} \mathrm{Al}$ final, esta manera de "ver" las cosas es el producto de un proceso de reflexión iniciado previamente, que fluye de las investigaciones en materia de acciones de interés público y que circula libremente a lo largo del trabajo al que da lugar la clínica jurídica.

De lo dicho se puede afirmar que luego de esta intensa experiencia, las herramientas de análisis, así como el contenido de lo jurídico, tendrán matices que en el imaginario del estudiante van a permitir superar el blanco y negro inculcado desde el positivismo-normativista. $Y$ como resultado de ello, el paradigma de la dogmática jurídica atenuará su vigor. Desde las acciones de interés público la labor del jurista desborda el problema de la dilucidación teórica de las normas con el objeto de elaborar modelos dogmáticos a expensas de los pre-existentes modelos normativos. Ahora lo jurídico, incorpora en la reflexión y desarrollo operativo la necesidad de anteponer a todo planteamiento o estrategia procesal la existencia de una determinada estructura de instituciones y sistema de reglas públicas que, sin estar debidamente explícitas, definen los derechos y deberes cuya garantía es sustantiva para las personas y para el funcionamiento del sistema jurídico-político en su conjunto: exigencias morales que otorgan contenido a los derechos fundamentales y cuya revalidación jurídica no pasa necesariamente por su reconocimiento legislativo.

\section{Los problemas teóricos más representativos a la luz de las acciones de interés público y su impacto institucional}

Del itinerario anunciado se desprenden planteamientos de orden teórico que revisan premisas de la dogmática jurídica. Este nuevo marco conceptual permite hacer frente a las dificultades del sistema legal para la defensa del interés público, con la opción de propiciar cambios en el sistema. A continuación veamos cuáles son los principales problemas y cuáles los aportes en esta línea: 
a) La legitimidad para obrar y la defensa del interés público

Una primera cuestión radica en la plataforma jurídica que respalda la acción necesaria para defender el interés público. $\mathrm{Al}$ respecto, de la ciencia jurídica tradicional se desprende la idea en cuya virtud la habilitación del sistema para que las personas defiendan sus derechos depende de que el interés que motiva la acción sea considerado legítimo, es decir, positivamente reconocido ${ }^{11}$. Se trataría de un interés que alude a cuestiones susceptibles de valorización patrimonial, o bien de un contenido moral, pero siempre pensando en que use trata de la defensa del propio círculo individualizado de actuación personal", esta es la perspectiva del Código Civil de 1984 que, sin duda, impedía imaginar la existencia de un interés distinto del individual y, por lo tanto, impensable el accionar para defender un interés público.

Esta situación ha sido aparentemente resuelta por el artículo $82^{\circ}$ del Código Procesal Civil de 1993. Desde dicha norma es posible pensar en la defensa de los intereses difusos, lo que vendría a ser una parte de los bienes jurídicos comprendidos en la noción interés público, según una línea argumentativa que procede de las investigaciones en materia de acciones de interés público. El artículo en cuestión establece:

Interés difuso es aquel cuya titularidad corresponde a un conjunto indeterminado de personas, respecto de bienes de inestimable valor patrimonial, tales como la defensa del medio ambiente, de bienes o valores culturales o históricos o del consumidor.

Pueden promover o intervenir en este proceso, el Ministerio Público y las asociaciones o instituciones sin fines de lucro que según ley o el criterio del Juez, ésta última por resolución debidamente motivada, estén legitimados para ello.

Sin embargo, precisamente, del último párrafo se desprende un elemento que ha sido utilizado en forma restrictiva por la judicatura, impidiendo la posibilidad de promover la defensa de los bienes jurídi-

11 Gorki Gónzales. "Relatoría sobre las acciones de interés público en el Perú». En: Las Acciones de Interés Público. Argentina, Chile, Colombia y Perú. Cuadernos de Análisis Jurídicos $\mathrm{N}^{\circ} 7$, p. 158. 
cos aludidos. La interpretación empleada podría resumirse en los siguientes términos: son titulares del interés difuso un conjunto indeterminado de personas en función del bien en cuestión, pero se es sujeto procesal en la medida en que esta habilitación provenga taxativamente de la ley. Como puede verse, esta perspectiva se basa en una interpretación literal de la norma, que termina por anteponer la inscripción registral de la persona jurídica, a la existencia del interés público que se predica como susceptible de protección.

Como consecuencia del trabajo de investigación en esta área, ${ }^{12} \mathrm{y}$ producto del trabajo de extensión realizado desde la clínica jurídica de la PUCP, se ha propiciado una perspectiva que afirma, más bien, la posibilidad de crear un sistema de defensa adecuadó y flexible que atienda al problema de fondo sin subordinar su solución al cumplimiento de formulismos vacíos de contenido ${ }^{13}$.

Pero el problema es más grave aún, pues combina la existencia de un Poder Judicial sin independencia en su actuación. Las consecuencias de este particular contexto en nuestro país han configurado un cuadro de creciente desprotección de los derechos fundamentales, ${ }^{14}$ de modo tal que no resulta extrańa la actuación del décimo cuarto Juzgado Civil de Lima en el caso promovido por la clínica jurídica de la PUCP sobre Nulidad de acto de constitución de las asociaciones The Edge Social Club y The Piano Social Club, por tratarse de asociaciones creadas en un contexto en el que resulta evidente el fraude a la ley y, por lo tanto, constituidas contraviniendo el orden público. ${ }^{15}$

En efecto, en una primera resolución de fecha 9 de julio último, ante la demanda interpuesta por el Ministerio Público a iniciativa de

12 Ibid., Pp. 160-161.

13 Solicitud de Intervención litisconsorcial, presentada por la Clínica Jurídica de la PUCP al Décimo Cuarto Juzgado Especializado en lo Civil de Lima, con fecha 6 de julio de 1999 , p. 6.

14 Gorki Gonzáles. Poder Judicial, Interés Público y Derechos Fundamentales en el Perú. Op. cit.

15 En efecto, la historia previa a su constitución da cuenta de una denuncia sobre discriminación racial ejercida por las empresas que administraban estas discotecas. Con el fin de evitar que se les sancione desde el Estado por afectar derechos del consumidor, optan por cambiar su forma jurídica a la de asociación, dando por hecho que esta nueva entidad les habilitaría la posibilidad de seguir ejerciendo discriminación escondiéndose tras la libertad de asociación. 
la clínica jurídica, ${ }^{16}$ el Décimo Cuarto Juzgado Civil de Lima, reconoce la existencia de ésta como asociación de hecho; sin embargo, ante la solicitud para que se nos reconozca como litisconsorte voluntario, ${ }^{17}$ la judicatura contradijo la citada resolución, disponiendo que, previamente, debía acreditarse el origen o creación formal de nuestra entidad. Para evitar mayores dilaciones, la clínica satisfizo el requerimiento, pero la respuesta del juzgado fue insospechable: en resolución $\mathrm{N}^{\circ}$ 6 de fecha 26 de julio de 1999, se reconoce a la clínica bajo la forma denominada "litisconsorte coadyuvante», institución inexistente en el ordenamiento procesal $y$, por lo tanto, de imposibles consecuencias jurídicas. La clínica ha pedido la nulidad de dicha resolución, enderezando el propio discurso teórico de la judicatura, sin perder de vista el interés público como finalidad.

Como se aprecia, entonces, el desarrollo de las investigaciones en materia de acciones de interés público tiene una efectiva incidencia en el ámbito operativo del derecho y su contribución permite ampliar el arsenal de armas para el litigio.

b) Discriminación y economía de libre mercado

Los cambios producidos en la política y en la economía durante la última década han propiciado un cuadro de fragmentación social enfatizando las diferencias entre las personas a partir de componentes cada vez más complejos. Se asiste así a un proceso de redefinición social impuesto por la lógica de la economía de libre mercado a la peruana: los estratos sociales de menores recursos reciben los residuos del proceso económico desarrollado en las esferas de altos ingresos del país. En esta nueva realidad -en la cual se prioriza el interés individualse profundizan las brechas culturales $y$, a la vez que se abren espacios de desarrollo y bienestar para un sector reducido del país, se impide su acceso a las grandes mayorías sociales del país.

16 El artículo 96 del Código Civil dice: «El Ministerio Público puede solicitar judicialmente la disolución de la asociación cuyas actividades o fines sean o resulten contrarios al orden público o a las buenas costumbres ..."

17 Ello supone que se nos considere parte demandante del proceso conjuntamente con el Ministerio Público, pues el asunto en cuestión nos atañe en la medida que se trata de un bien jurídico de interés público.

18 Paul Paredes. Discriminación en el empleo tras la política laboral de ajuste y estabilización de la economía (1991-1997), Op. cit. 
Los efectos devastadores del sistema han sido puestos en evidencia en diversas investigaciones en materia de acciones de interés público. Y como ejemplo reciente de ello, se tienen los trabajos de Paredes ${ }^{18}$ y Neves ${ }^{19}$ que dan cuenta de un contexto en el cual, producto de la política laboral de ajuste y flexibilización se ha erosionado gravemente el Estado de Derecho, ${ }^{20}$ propiciando la precarización del empleo y ampliado el espacio para las prácticas discriminatorias. En efecto, no obstante la dación de normas como la Ley No 26772 y su reglamento, sobre prohibición de discriminación en las ofertas de empleo, ${ }^{21}$ las propias investigaciones han destacado la insuficiencia de tales disposiciones para hacer frente a los problemas de discriminación en el acceso al empleo, para contrarrestar las prácticas de discriminación indirecta y para brindar disposiciones sobre materia probatoria, que impidan que la carga de la prueba recaiga sobre el afectado ${ }^{22}$.

En esta misma dirección las prácticas discriminatorias se abren paso en diversas direcciones. Como se vislumbra desde el trabajo de Paredes, ${ }^{23}$ el énfasis de la lógica neoliberal no considera debidamente el factor humano y, producto de este enfoque, la libertad de contratar adquiere un valor sobredimensionado: una lógica que permite subordinar el ejercicio de derechos constitucionales como el de la igualdad y el principio de la no discriminación. Precisamente, ha sido tarea de la clínica jurídica revertir esta perspectiva interpretativa para enfrentar un caso de enorme impacto social: la discriminación para el ingreso a diversas discotecas de la ciudad.

La reflexión encaminada a establecer que los derechos constitucionales no son absolutos, ha sido propuesta desde trabajos como el de Paredes. ${ }^{24}$ Desde ahí, se ha emprendido la tarea de demostrar que el ejercicio de los derechos tiene el límite referido al contenido esencial

19 Javier Neves Mujica. Op. cit., p. 147.

20 En tal sentido, Neves sostiene que: "Lo primero que se debe resaltar, desde mi punto de vista, es que el marco institucional en el Perú de hoy, se encuentra seriamente afectado. El Poder Ejecutivo ha destruido el Estado de Derecho, con la colaboración activa o pasiva del Congreso, a través de la intervención sobre diversos organismos autónomos, encaminada a impedir su libre funcionamiento...». Ibid., p. 134 (el subrayado es nuestro).

21 En el fondo la norma en cuestión es la evidencia más clara de la existencia de prácticas discriminatorias.

22 Paul Paredes. Op. cit., p. 77.

23 Ibid, p. 73.

24 L. cit. 
de la libertad protegida y el que surge para evitar la colisión con otro derecho fundamental. La clínica jurídica ha tomado la posta en esta "empresa" y, precisamente, en el caso de la discriminación para el ingreso a ciertas discotecas de nuestra ciudad, se ha convertido en parte procesal, primero como "Tercero Coadyuvante" en un proceso constitucional de amparo promovido por las Discotecas The Edge y The Piano contra el Instituto de Defensa de la Competencia y la Propiedad Intelectual (INDECOPI). En este caso, se cuestionaba la aplicación de sanciones administrativas que esta entidad estatal había anunciado contra las mencionadas discotecas por infringir la Ley de Protección al Consumidor. La resolución judicial que puso fin al proceso, por lo demás, deplorable, ${ }^{25}$ confirma la grave crisis por la que atraviesa el Poder Judicial en su conjunto.

En un segundo momento, la clínica ha continuado con el caso en otra instancia, perfilando, esta vez, argumentos ya trabajados en el itinerario de investigaciones en materia de acciones de interés público. Se ha desarrollado, en la perspectiva indicada, un afinamiento del concepto "orden público". Esta tarea surge a propósito del cambio de forma jurídica realizado por las discotecas en cuestión, en busca de continuar con sus prácticas discriminatorias escondiéndose tras las libertades de asociación y contratación, para evitar de este modo la presión ejercida desde el Estado a través de INDECOPI. Se trata de demostrar, en consecuencia, que dicho cambio obedece a un fin que vulnera el orden público, pues no hace sino revestir de forma jurídica una práctica lesiva de derechos constitucionales. Se trata, en suma, de afirmar el concepto "orden público" como no subordinado a la infracción de un texto legal expreso, siendo necesario que los tribunales establezcan en cada especie si el objeto de la convención o de la obligación es contrario a las necesidades del actual orden público. ${ }^{26}$

En la línea propuesta, se ha argumentado sobre la necesidad de circunstanciar los hechos que rodean al cambio de forma jurídica de las discotecas. De este razonamiento, deriva, entonces, que la causa del acto jurídico -es decir, la motivación que ha empujado al autor a

25 Así ha sido calificada, incluso, por Javier Neves. Op. cit., p. 147.

26 En Solicitud para la intervención del Ministerio Público para la interposición de demanda sobre nulidad de constitución y disolución de asociaciones. Presentada por Clínica Jurídica de la PUCP al Fiscal de la Nación con fecha 18 de mayo del presente año, p. 6 del escrito. 
efectuarlo- puede ser recogida a partir del contexto sociológico que rodea a la materia controvertida. ${ }^{27}$ Esta perspectiva permite establecer, con mayor consistencia, que la motivación que está en el fondo de dicho acto es, ciertamente, contraria al orden público y por lo tanto dicho acto es nulo, desbordando, así, el análisis formalista de las normas, el cual deviene insuficiente.

Una respuesta positiva de la judicatura, en este sentido, contribuiría a ampliar los argumentos para enfrentar estas prácticas incompatibles con la tolerancia, el pluralismo y la democracia. En todo caso, como ha sido puesto en relieve por Neves, ${ }^{28}$ la vulneración del derecho a la igualdad y del principio de no discriminación, "en nuestro país es absolutamente generalizada, en el ámbito laboral y fuera de él» y el Poder Judicial, como ha sido permanentemente reiterado no ha contribuido mayormente a hacer frente a esta realidad. Queda por lo tanto, mucho por hacer en este difícil contexto y, las acciones de interés público son un instrumento estratégicamente fundamental para ello.

\section{Las acciones de interés público como espacio institucional y como instrumento de articulación institucional: aciertos y dificultades}

Las instituciones son la base sobre la cual se articula la vida en comunidad. Para ser tales, es decir, para contar con legitimación social, deben expresar, con intensidad, las convicciones o acuerdos respecto de cómo deben ser satisfechas determinadas necesidades o de cómo es que debe ser el ordenamiento social requerido. En otras palabras, un sistema social y político debe contar con reglas claras, mecanismos idóneos que sirvan para afirmar dichas reglas y un contexto de legitimidad social, es decir, de valores, convicciones y reglas éticas compartidas antes que impuestas- que hagan posible la verificación y el respeto de las instituciones.

El espacio configurado por el denominado interés público, alberga los componentes que hacen posible el diseño de las reglas y la formulación de los mecanismos para afirmar dichas reglas. Más aún, como se desprende de los distintos trabajos de investigación en materias de 
acciones de interés público, el interés público se configura a partir de los valores, convicciones y reglas éticas compartidas por el grupo o comunidad. Se puede afirmar, por ello, que las acciones de interés público son un ámbito desde el cual se perfila el sentido y la calidad de las instituciones.

En el ámbito de las acciones de interés público, la enseñanza del Derecho encuentra -como ha sido dicho líneas atrás- elementos para repensar y reformular sus posibilidades en sus dos vías: qué enseñar y cómo enseñar. Es a partir, de este fenómeno que es posible, entonces, incidir efectivamente en el ordenamiento institucional, para formular propuestas de reforma en el ámbito de las reglas legales, para desarrollar pistas de interpretación que permitan encausar con mayor eficacia y justicia los conflictos de derechos, pero además para propiciar un cambio en el imaginario social que sustenta la idea de lo jurídico y de las instituciones, como entidades abstractas y susceptibles de ser impuestas. En esta tarea se ubica el trabajo desarrollado por el grupo de referencia de la Pontificia Universidad Católica.

En ese orden de ideas, el terreno de las acciones de interés público ha sido propicio para confrontar los intereses institucionales de entidades que han venido trabajando en temas semejantes a los que se enmarcan en el discurso de las denominadas acciones de interés público. Es el caso de algunas ONGs, principalmente, la Sociedad Peruana de Derecho Ambiental y en menor medida el Instituto de Defensa Legal, y de entidades públicas como la Defensoría del Pueblo y el Ministerio Público. En otras palabras, el arsenal teórico generado desde las reflexiones en materia de acciones de interés público, permite articular un lenguaje común respecto de intereses comunes y, en esa medida, constituye un instrumento flexible y útil para avanzar en la mejor definición de las libertades y derechos fundamentales y en el diseño de estrategias de defensa compartidas, -en la perspectiva del interés público- por un conjunto de instituciones de la sociedad civil.

Gracias a este desarrollo, la articulación regional también ha sido posible pues la reflexión derivada de las investigaciones en acciones de interés público permite un trabajo de comparación institucional sin precedentes. Es a través de esta perspectiva que los distintos cuadros de indefensión del interés público en países como Chile, Argentina o Perú -por ejemplo, la vulneración de derechos fundamentales, así como los mecanismos constitucionales para su defensa-, pueden ser entendi- 
dos en función de diferencias y semejanzas respecto de lo que ocurre en cada país, de modo tal, que a partir de ello, es posible entender mejor la propia realidad. Las acciones de interés público proporcionan el contexto teórico y metodológico para hacer posible esta aproximación.

En cualquier caso, las mayores dificultades para el trabajo en red a nivel nacional o regional, provienen -en el caso peruano- de la incertidumbre general que envuelve el panorama institucional de nuestro país. Incertidumbre que impide la posibilidad de planificar en el largo o mediano plazo y que acrecienta el énfasis en lo privado como norma de vida. Junto a ello, la débil institucionalidad existente -o más bien, las pocas instituciones no intervenidas por el gobierno-, impide avizorar un horizonte claro, la máxima de este proceso parece ser simplemente "sálvese quien pueda". Este estado de cosas contamina en forma perniciosa cualquier avance democratizador desde las acciones de interés público y obstaculiza seriamente la posibilidad de generar un mayor desarrollo. Sólo pensar en la situación por la que atraviesa el Poder Judicial en el Perú, es más que un ¿pretexto? para cancelar cualquier intento de argumentación que ilumine la ensombrecida función de juzgar.

VI Redimensionado la utopía: los futuros desafíos para las acciones de interés público y la enseñanza del derecho

El derecho como instrumento producido por un legislador omnicomprensivo, hiper-racional, capaz de dar reglas a todos los habitantes de un país, sin tomar en cuenta las diferencias culturales, sin dejar espacios en blanco, es una utopía o, más bien, una anti-utopía: un lugar de ninguna parte que, en realidad, nadie quiere ni anhela. La excepción, ciertamente, se configura cuando se antepone la satisfacción de fines políticos concretos ajenos a la preservación de los valores de la democracia, el pluralismo y la tolerancia.

El derecho como una herramienta para enriquecer la interacción social y como espacio de comunidad, producido desde múltiples ámbitos de la vida social, es el lugar al que se alude en las reflexiones en materia de acciones de interés público. La valoración de instancias tales como el Poder Judicial, esperando de él respuestas que permitan 
corregir los errores del sistema jurídico-político, la importancia otorgada a las entidades de la sociedad civil, como las ONGs, el papel asignado a instancias distintas del Poder Judicial, para contribuir a la solución de los conflictos, en suma, marcan una definición preliminar sobre las limitaciones del ámbito de lo jurídico y sus fuentes en la visión tradicional, y plantean la necesidad de redimensionar la utopía.

Quizás en esto último radica el sentido utópico de los futuros desafíos de las acciones de interés público y del papel que en ese sentido deberá cumplir la enseñanza del Derecho. En el Perú, se ha dicho, la institucionalidad ha sido prácticamente destruida por el actual gobierno, el punto de partida está ahí precisamente: que exista una conciencia plena de esta carencia básica, para orientar esfuerzos en pos de su re-construcción. Las acciones de interés público deberán dar mayor énfasis a las estrategias que a partir de casos relevantes propicien respuestas a la carencia institucional.

Insistir en la necesidad de obtener respuestas jurisdiccionales buscando enderezar los vacíos y errores de la legislación vigente, es un primer punto en esta agenda. La propia dinámica docente debe insistir en la importancia de la responsabilidad de los jueces en esta materia y dar el espacio para el desarrollo de una metodología de comprensión de lo jurídico que pondere, suficientemente, el trabajo argumentativo en clase. Esta estrategia tendrá un impacto inmediato en la enseñanza (qué se enseña y cómo se enseña), pero además tendrá un efecto multiplicador: propiciará las bases de una mayor conciencia respecto de la necesidad de reformar el Poder Judicial, sin intervenciones políticas que lo conviertan en un órgano dependiente, expuesto a la interferencia del Ejecutivo, tal como ocurre en la actualidad. Las investigaciones orientadas a valorar los avances en esta área son una prioridad.

Un segundo aspecto deberá incidir en el trabajo más fluido y coordinado con entidades estatales como la Defensoría del Pueblo o INDECOPI. Hay que generar las condiciones para compartir espacios que permitan fortalecer de Interés Público y, a partir de ello, desarrollar acciones en el ámbito administrativo o judicial. En este esfuerzo, habría que pensar la posibilidad de convocar a algunas municipalidades, pues en el fondo, pese al actual contexto, éstas son un espacio alternativo de la política en función del interés público que no se encuentra necesariamente contaminado por la injerencia del régimen de turno. 
Una estrategia que ya se encuentra en curso es la que proviene del «Foro de Acciones de Interés Público». La idea propuesta implica perseverar en la misma lógica de cooperación con la que se ha venido trabajando, buscando reforzar la relación con organizaciones incorporadas en la línea de apoyo y promoción de los intereses públicos. De este modo, se lograría una mejor convocatoria y un mayor impacto en la comunidad. En esta dirección el trabajo de la Clínica Jurídica debe apostar a la consolidación de un grupo de referencia que permita una mayor cobertura para el aporte y diversificación de las herramientas útiles para la defensa de los bienes jurídicos de interés público, así como para el fortalecimiento de los mecanismos de protección.

Se ha logrado convocar la participación de una entidad importante en el área de la investigación y promoción de las ciencias sociales en el Perú: DESCO (Centro de Estudios para la Promoción y el Desarro1lo). Esta ONG ha desarrollado importantes contribuciones en áreas del quehacer ciudadano y su relación con la política y la economía. Al margen de las varias series de publicaciones en libros, boletines y revistas, DESCO cuenta con una publicación bimestral de circulación nacional llamada QUEHACER, la cual constituye un espacio privilegiado y autorizado desde el que se tratan diversos temas de interés público en el país, aportando con opiniones críticas, ensayos y entrevistas a la mejor comprensión de los temas en cuestión. Sin duda, el aporte interdisciplinario que DESCO podría brindar al desarrollo del proyecto será fundamental, permitiendo lograr un rápido posicionamiento del Foro en el escenario del debate y la opinión pública.

Crear condiciones que hagan posible la vigencia de los derechos y libertades públicas se entrelaza con la necesidad de afianzar y construir instituciones políticas en el sistema democrático. Hay que Insistir, por ello, en la importancia de la deliberación ciudadana en la formulación de los principios sobre los que se funda el orden jurídico-político; principios que sólo serán viables en tanto las propias instituciones políticas permitan su satisfacción en la práctica cotidiana. Redimensionar la utopía significa, entonces, trabajar en esta línea como argumento contra el autoritarismo y la visión unidimensional del derecho; involucra, auspiciar desde la docencia, una visión del derecho comprometida con estas motivaciones contra la postura pretendidamente "aséptica" o "técnica» de la enseñanza tradicional. 